\title{
A quantitative model of technological catch-up
}

\author{
H.Gholizadeh $^{1}$ *, A.Bonyadi Naeini ${ }^{2}$, A.Moini ${ }^{2}$ \\ ${ }^{1}$ Department of Progress Engineering, Iran University of Science and Technology, Ave. Narmak, 16846-13114-Tehran, Iran \\ ${ }^{2}$ Assistant Professor, Department of Progress Engineering, Iran University of Science and Technology, Narmak, Tehran, Iran \\ *Corresponding author E-mail: Hossein_gholizadeh@ind.iust.ac.ir
}

Copyright $(\odot) 2015$ H.Gholizadeh et al. This is an open access article distributed under the Creative Commons Attribution License, which permits unrestricted use, distribution, and reproduction in any medium, provided the original work is properly cited.

\begin{abstract}
This article presents a quantitative model for the analysis of technological gap. The rates of development of technological leaders and followers in nanotechnology are expressed in terms of coupled equations. On the basis of this model (first step) comparative technological gap and rate of that will be studied. We can calculate the dynamics of the gap between leader and follower. In the Second step, we estimate the technology gap using the metafrontier approach. Then we test the relationship between the technology gap and the quality of dimensions of the Catch-up technology which were identified in previous step. The usefulness of this approach is then demonstrated in the analysis of the technological gap of nanotechnology in Iran, the leader in Middle East and the world. We shall present the behaviors of the technological leader and followers. At the end, analyzing Iran position will be identified and implying effective dimension of catch-up Suggestions will be offered which could be a fundamental for long-term policies of Iran.
\end{abstract}

Keywords: Technological Leapfrogging; Technological Gap; Path Dependency; Windows of Opportunity; Metafrontier; Stochastic Frontier.

\section{Introduction}

For developing countries, considering the gap and the quick rate of technology growth in developed countries, those strategies are significantly important which lead to an increase in the rate of technology growth and minimizing the gap in short term. There are various ways of achieving up-to-date technology. Among the researches are those which are dedicated to the solutions and significant factors the developed technology pioneers have experienced. In another category, there are researches focusing on optimizing approach, updating paths and methods, using back-wardens advantages. Some believe the opportunity window to be the best choice, saying that the final purpose might be the same as that of developed countries, yet the path taken is not necessarily the same. They argue that considering the native strategies and circumstances is important and they believe using the opportunities is the golden key to technology catchup. Due to this fact, they do not take the backhandedness a disadvantage, rather an advantages to use opportunities and avoiding the sequences of being pioneer. They consider using the window opportunity and avoiding dependence as strategies to quick access to successful technologies.

In this study, first we briefly present some of the definitions and notions in quick access and leap. Considering the special situation of Iran in the region and world, in case there is a significant gap, and acing that technology is amongst country's strategies according to the upstream documents, the solution will be quick access to that technology taking a minimum cost and time approach. At the end of that part, we can present some approaches to quick access to technology, each of which to be used in the specified field. In the second part, using a quantitative approach, the conditions of Nano technology in Iran is studied as compared to the Middle Eastern and international competitors. The purposes include determining technology gap, determining whether or not the path and approach Iran has taken works and determining if the path would lead to a decrease in the gap. At the end, using the significant factors mentioned in part I, suggestions could be presented to promote the approach taken by Iran about Nano technology. 


\section{Definitions of quick access and affecting dimensions}

A necessary part of development process in countries beyond the pioneers of technology and economy, is learning and dominance over tasks in short terms. This is known as quick access. In this meaning, quick access does not solid copying [1] Countries with the longest distance with technology pioneers mostly depend only on foreign knowledge, importing technology via equipments, machinery, or under-licensed production and even reverse engineering and copying [2] Veblen (1915) was the first person to compare economic rating of countries and identifying the factors involved and primary industrial advantages. In 1966, Richard Nelson and Edmond Philips introduced the notion of quick access from other countries, which was among the most interesting ideas in modern economic growth. Yet, this is officially credited to Gerschenkron (1962) who stated that countries behind the technology gap are able to decrease their distance from leading countries through imitating the technologies. Gerschenkron believed the discussion on quick access must be added to the veblen's ideas. He showed that late-developed countries are able to accelerate the technology achieving growth through developed technologies of pioneer leading countries. The well-known work by Gerschenkron, "economic development in a historical prospective", was an exception at its time. He explicitly considers inability to quick access as the reason for development of Europe in the second half of the 19th century. After Nelson and Philips, Abramovitz (1986) studied and reviewed Gerschenkron's ideas. He showed that the technology gap rate depends on the followers' ability to receive technology streams from the pioneers. Abramovitz' article, "catching up, forging ahead and falling behind" made the notion of quick access a part of standard vocabulary for development economists[2], [3] .

\section{Domestic structures}

According to Madision and Greschenkron, growth and moving towards development in technology are not achieved by purchasing or using ready-made solutions, rather they depend on dominance and expertise on all technology components. Chandler [4], [5] argues that importing technologies is fruitless without synchronizing with native innovative efforts and establishing relations with market demands. Infrastructure must be corrected and there is a need in investing in educational activities.

Knowledge aggregation: an important remark about pioneer countries was that they aggregate knowledge in developing sections and this acted as a growth factor for them [6], [7]. Technology imparting mechanisms leading to quick access have been subject to change during time [8] Historical evidence show that technology imparting occurs through domestic aggregation of technology, as a vital factor to growth [9].

Primary conditions: in the literature the term primary condition is mentioned, although making examples has made it contradictory. For example, human resources expertise in central Europe such as Czech is sometimes neglected. For example Dosi [10] argues that primary advantages cannot predict future events.

Opportunity window: according to Gerschenkron, under special circumstances back warded countries are able to grow faster than pioneer countries. In his opinion, huge gaps provide the biggest opportunities for back warded countries to imitate and quick access which lead to convergence in development levels [4] Perez and soete and Unger show two opposite situations for possibility of technology quick access, and optimistically claim that the current conditions will remain to be the same at future, especially in the leap direction o develop. In this regard, it has been argued that new technologies are the opportunity window for leap. Contrarily, Unger argues that developing countries, due to needing new skills and also rare entrepreneurship resources, will be "on the edge of vain rotation".

Institutional and social circumstances: Abramovitz argues that a country is able to develop rapidly in which backwardedness is not due to incompetency [4], [11] However, when the country is technologically back warded, but enjoys social advantage, the situation is provided for quick growth [12] Abramovitz considers such facilities as international technical communications channels, international trade circumstances, and direct foreign investment as significant in knowledge distribution [13-15].

Macro policy-making and development plan: Tunzelmann (1995) shows that in dynamism perception, the appropriate technology to choose is not the one that is compatible with our advantages and talents, rather the quality of talents increase for long term advantage is significant $[14,16]$ He believes that in any case of successful quick access, it begins with focusing on the process. Also, he argues that other things the same, the ability development opportunity will be higher as compared to the case in which the technology is imported as key in hand or as direct foreign investment. This also applies to native technological capacity. What opportunities and circumstances for achieving the technology must be used depends on the native efforts, complementarily and imported technology perfectionism [4], [11], [17] Investment: Ozawa (1992) developed the development dynamic scheme of "facilitating direct foreign investment". Direct foreign investment operation acts as a catalyst for industrial development and technological leap. He tried to involve a developmental function of multi-national companies in the theory of open economic development [18] A similar attempt from Dunning undertaken in which the multi-national companies activities were taken as an exogenous variable affecting the competitive advantage and technological leap [15]. 


\section{A quantitative formulation of the model}

In attempting to assess and analyze the role of technology transfer, a number of specific questions are in order. Perhaps the most important concern the degree to which technology transfer can assist the rate of development of the follower country in a specific Technology.

The purpose of this section is to develop a quantitative method for comparing the rates of development of the leader and follower, to allow for an evaluation of these and related issues. As noted above, it is assumed that the leader develops in a manner independent of the follower. Technological proficiency may be measured by some quantity P. Use of P in a quantitative model would not be sensible, however, since any function of P might just as well have been used and would change the model's properties. We introduce a dimensionless measure $\mathrm{X}$, that is, some function of $\mathrm{P}$ :

$X=f(P)$

$\frac{\mathrm{dx}_{\mathrm{L}}}{\mathrm{dt}}=\mathrm{K}_{\mathrm{L}}$

$X_{L}(t)=x_{L}^{o}+K_{L} t$

Thus, we are assuming that there is some measure of technology that increases linearly in time for a leading (or decoupled) country. The development of the follower must be measured in a similar form, though this will not, of necessity, imply a linear increase with time for $\mathrm{x}$, (technological know-how) of the follower. From equations below, we can conclude that the simplest function representation of the connection between the measures $\mathrm{X}$ and $\mathrm{P}$ is:

$\mathrm{x}=\ln \mathrm{p}$

The first contribution $\mathrm{K}_{\mathrm{F}}$ represents the indigenous development of the follower and the second contribution represents that of technology transfer.

$\frac{d x_{F}}{d t}=K_{F}+f_{1}\left(x_{F}\right) f_{2}\left(x_{L}, x_{F}\right)$

In many cases, $\mathrm{K}_{\mathrm{F}}$ is significantly less than the second transfer term and progress is, thus, dependent on the gap between leader and follower. As the gap decreases, the contribution of technology transfer would logically become less significant, while for large gaps, the follower has a large reservoir from which to draw. The functions of $\mathrm{f}_{1}\left(\mathrm{x}_{\mathrm{F}}\right)$, $\mathrm{f}_{2}\left(\mathrm{x}_{\mathrm{L}}, \mathrm{x}_{\mathrm{F}}\right)$. are generalized functions implying a dependence of the follower's rate of progress on his technological proficiency in the field and on the gap between him and the leader. In this case, the simplest form is:

$f_{2}\left(x_{L}, x_{F}\right)=\left(x_{L}, x_{F}\right)$

We choose $\mathrm{f}_{1}\left(\mathrm{x}_{\mathrm{F}}\right)$ to be a dual-valued function, such that for small $\mathrm{x}_{\mathrm{F}}$, it is zero, but when $\mathrm{x}$, has crossed a particular threshhold, it is a constant, $\mathrm{k}$,. For example, an industrial state such as Japan is able to pursue a given technology once a decision has been made to do so, but a less industrialized state may not have the capability even to absorb available technology. Until this capability is developed, the value of the function $f_{1}$ is zero.This function form of $f_{1}\left(x_{F}\right)$ is consistent with empirical experience. For countries with little technological development of their own, there is almost nothing they can absorb in the form of technology transfer. Once they have gained a minimal amount of knowledge (the threshold point), however, they can begin to absorb this externally developed component.

$\frac{\mathrm{dx}_{\mathrm{F}}}{\mathrm{dt}}=\mathrm{K}_{\mathrm{F}}+\mathrm{k}_{\mathrm{T}}\left(\mathrm{x}_{\mathrm{L}}, \mathrm{x}_{\mathrm{F}}\right)$

$\frac{\mathrm{dx}_{\mathrm{F}}}{\mathrm{dt}}+\mathrm{K}_{\mathrm{T}} \mathrm{x}_{\mathrm{F}}=\mathrm{K}_{\mathrm{F}}+\mathrm{k}_{\mathrm{T}} \mathrm{X}_{\mathrm{L}}$

$\frac{d x_{F}}{d t}+K_{T} x_{F}=K_{F}+K_{T} x_{L}^{o}+K_{T} K_{L} t$

This is an inhomogeneous linear differential equation. The general solution to the entire equation consists of a general solution $\mathrm{X}^{\mathrm{H}}$ to the homogenous equation (right hand side equals zero) plus any particular solution $\mathrm{X}^{\mathrm{P}}$ to the entire, no homogenous equation. Thus, $\mathrm{K}_{\mathrm{F}}=\mathrm{X}^{\mathrm{P}}+\mathrm{X}^{\mathrm{H}}$

The solution to the homogenous equation is: $\mathrm{X}^{\mathrm{H}}=\mathrm{Ce}^{-\mathrm{k}_{\mathrm{T}}}$

Where $\mathrm{C}$ is a constant of integration we can also assume that a particular solution will have the same form as the solution for the leader. Thus: $\mathrm{x}_{\mathrm{P}}=\mathrm{A}+\mathrm{Bt}$ 
Plugging this into eq. above we find that:

$$
\begin{aligned}
& B+K_{T} A+K_{T} B t=K_{F}+K_{T} x_{L}^{o}+K_{T} K_{L} t \\
& B=K_{L}, \quad A=\left(K_{F}-K_{L}\right) / K_{T}+x_{L}^{o} \\
& K_{F}(t)=\left(K_{F}-K_{L}\right) / K_{T}+x_{L}^{o}+K_{L} t+C e^{-k_{T}^{t}}
\end{aligned}
$$

To solve for the constant of integration, $\mathrm{C}$, we use an initial condition. $\mathrm{t}=0$

$$
\begin{aligned}
& \mathrm{K}_{\mathrm{F}}(0)=\mathrm{x}_{\mathrm{F}}^{\mathrm{o}}, \mathrm{C}=\mathrm{x}_{\mathrm{F}}^{\mathrm{o}}-\mathrm{x}_{\mathrm{L}}^{\mathrm{o}}-\left(\mathrm{K}_{\mathrm{F}}-\mathrm{K}_{\mathrm{L}}\right) / \mathrm{K}_{\mathrm{T}} \\
& \mathrm{K}_{\mathrm{F}}(\mathrm{t})=\mathrm{x}_{\mathrm{L}}^{\mathrm{o}}+\mathrm{K}_{\mathrm{L}}^{\mathrm{t}}-\left(\mathrm{K}_{\mathrm{L}}-\mathrm{K}_{\mathrm{F}}\right) / \mathrm{K}_{\mathrm{T}}-\underset{(\text { initial gap })}{\left[\left(\mathrm{x}_{\mathrm{L}}^{\mathrm{o}}-\mathrm{x}_{\mathrm{F}}^{\mathrm{o}}\right)-\underset{(\text { final gap })}{\left(\mathrm{K}_{\mathrm{L}}-\mathrm{K}_{\mathrm{F}}\right)} / \mathrm{K}_{\mathrm{T}}\right] \mathrm{e}^{-\mathrm{k}_{\mathrm{T}} \mathrm{t}}}
\end{aligned}
$$

The form of this solution reminds one of other cases of coupled dynamic behavior. The first line of the solution represents the "steady state" solution, for large t, and the second line is the transient solution, which may be important for smaller time spans. In considering the steady-state portion, we note that the first two terms, $x_{L}^{o}+K_{L}^{t}$ represent the progress of the leader, $\mathrm{x},(\mathrm{t})$. The remaining term, $\left(K_{F}-K_{L}\right) / K_{T}$ represents the "steadystate" gap between leader and follower. It is important to note that the gap does not necessarily vanish for large t. This conforms to observed behavior and is consistent with the assumption that the leader maintains a constant effort to develop new technology, as represented in eq.the gap:

$$
\begin{aligned}
& G=\left(X_{L}-X_{F}\right) \\
& =\left(\mathrm{K}_{\mathrm{L}}-\mathrm{K}_{\mathrm{F}}\right) / \mathrm{K}_{\mathrm{T}}+\left[\left(\mathrm{x}_{\mathrm{L}}^{\mathrm{o}}+\mathrm{x}_{\mathrm{F}}^{0}-\left(\mathrm{K}_{\mathrm{L}}-\mathrm{K}_{\mathrm{F}}\right) / \mathrm{K}_{\mathrm{T}}\right] \mathrm{e}^{-\mathrm{k}_{\mathrm{T}} \mathrm{t}}\right. \\
& \quad(\text { final gap }) \quad \text { (transient) }
\end{aligned}
$$

When the initial levels are equal, as is frequently the case, the steady-state" solution for large $t$ is:

$G_{\infty}=\left(K_{L}-K_{F}\right) / K_{T}$

In brief, we assume a measure of technology proficiency $\mathrm{X}$ so that for the leader:

$\frac{d x_{L}}{d t}=K_{L}$

And for the follower:

$\frac{d x_{F}}{d t}=K_{F}+k_{T}\left(x_{L}, x_{F}\right)$

The constants $K_{L}, K_{F}$ measure the two countries' intrinsic learning rates and $K_{T}$ the transfer coefficient. These equations have the solution

$x_{L}(t)=x_{L}^{o}+K_{L}^{t}$

$x_{F}(t)=x_{L}(t)-G_{\infty}-\left(G_{0}-G_{\infty}\right) e^{-k_{T} t}$

Where $G_{0}=x_{L}^{o}-x_{F}^{0}$ (the initial gap), and $G_{\infty}=\left(K_{L}-K_{F}\right) / K_{T}$ (the eventual gap) Prior to the analysis of a single case, it is useful to examine the application of this model in a series of general cases. Different forms of generalized behavior can be illustrated by examining the relative rates of technological development that are associated with varying values of $K_{F} \cdot k_{T}, K_{L}$ (The reader should note that $K_{F} \cdot k_{T}, K_{L}$, are in units of years- $y^{-1}$ ), we compare the effects of $K_{F}$ and $K_{L}$ on the technological gap assuming that the initial gap is zero. One can distinguish between two general cases; when the indigenous rates of development of leader and follower are relatively similar $\left(K_{F}=K_{L}\right)$ and when the leader's development is much greater than that of the follower $\left(k_{T}>>K_{L}\right)$.

A third case in which the follower's rate is greater than that of the leader is possible, but in this case, the follower would eventually become the leader and is, thus, included in the first case. A more detailed analysis of this third case will be presented in a subsequent paper. In cases where the indigenous rates of development are similar, so that the rate of the leader is only marginally greater than that of the follower, the asymptotic level of the gap is relatively small. In contrast, when the indigenous rate of development of the follower is significantly smaller than that of the leader, the gap grows 
much more rapidly at the beginning and the "steady-state" gap is far larger than that in the previous case. For example, for a fixed $\mathrm{k}$, (rate of transfer) and a given $K_{L}=0.5 y^{-1}$, values of $K_{F}=0.4 y^{-1}$, and $K_{F}=0.2 y^{-1}$, yield very different size gaps. For the lower level of indigenous development, the gap opens quickly and reaches a level that is over a factor of 2.5 greater than that for $K_{F}=0.4$ ' in 25 years.

For the case of a small $K_{F}$ the gap is relatively larger and takes longer to reach a steady state. The rates through which the technological gap changes are very sensitive to the value of $K_{T}$, the rate constant for technology transfer. For a given $K_{L}$ and $K_{F}$, different values of $K_{T}$ result in various types of behavior For a relatively high value of $K_{T}$ the gap reaches a fixed and relatively low level in a short period of time. For $K_{L}=0.5 y^{-1}, K_{F}=0.2 y^{-1}$, the gap reaches about two thirds of its "steady-state" value in six years when $K_{T}=0.2 y^{-1}$. When $K_{T}=0.06$, this value is not reached until 20 years have passed, and the "steadystate" gap is more than 3 times as great as when $K_{T}=0.2 y^{-1}$. For a $K_{T}=0.02$, the "steadystate" gap is 10 times greater than for $K_{T}=0.2 y^{-1}$.

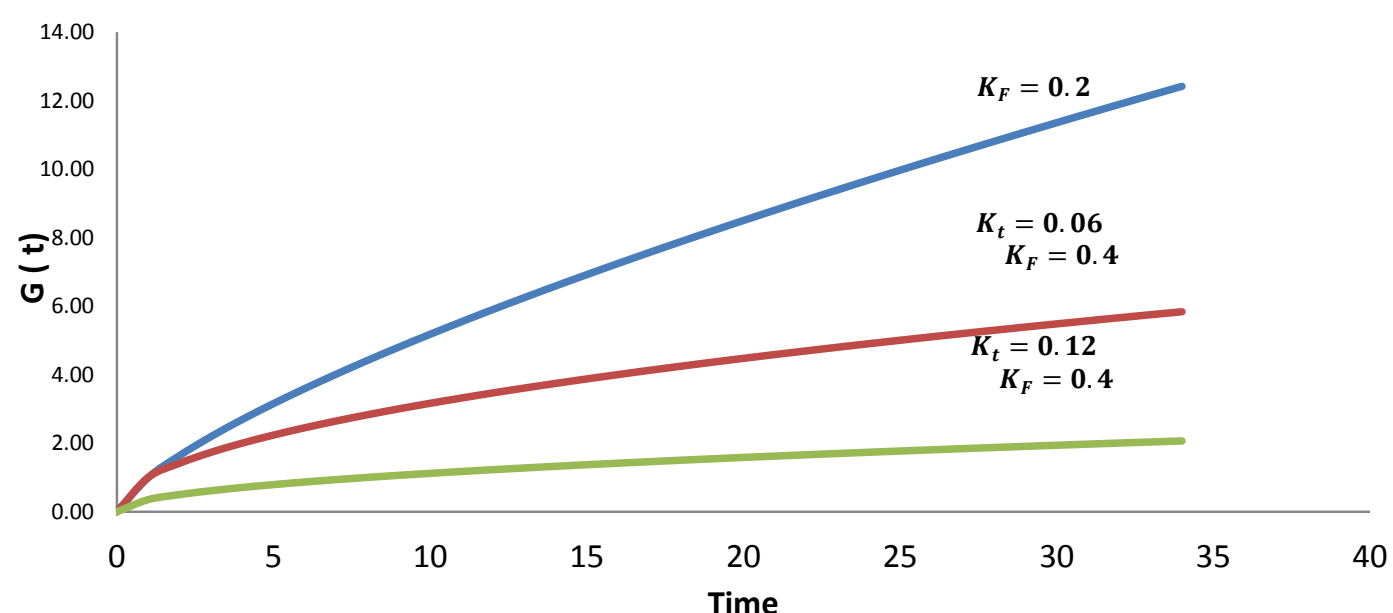

Fig. 1: Relative Effects of the Different Rate Constants on the Dynamics of the Technological Gap and on the Steady State Value ) $K_{F} K_{t}($

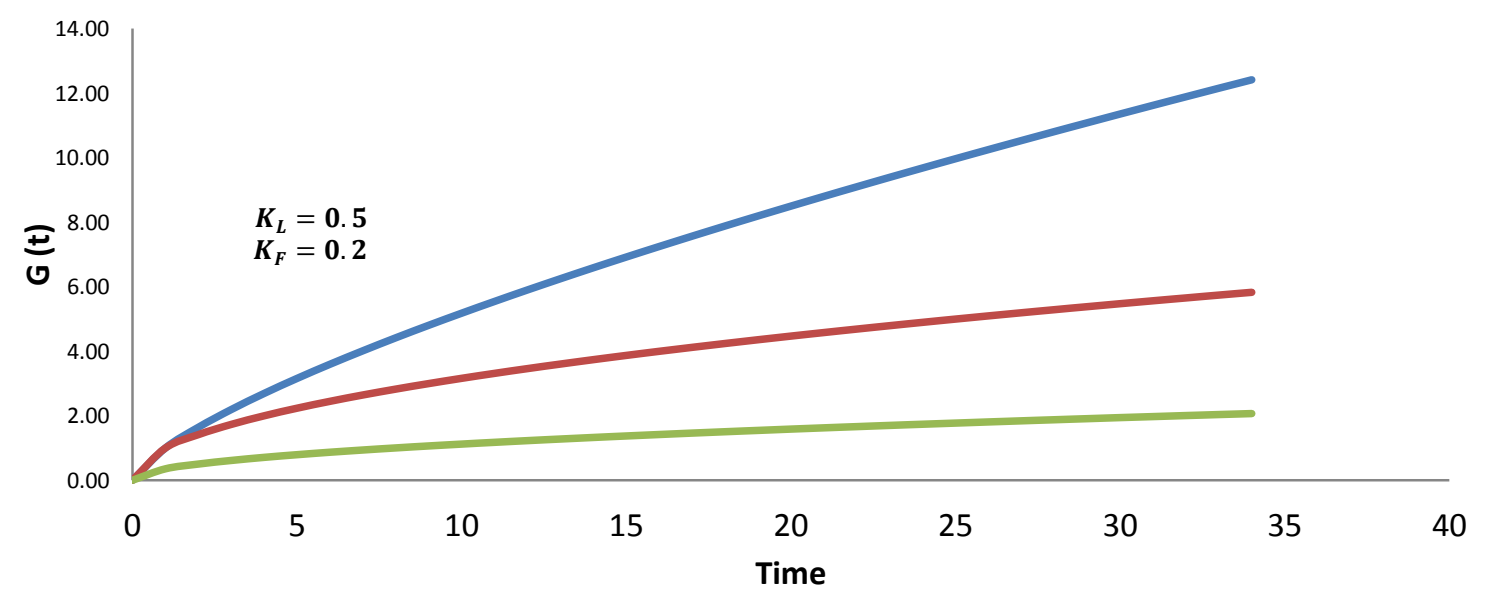

Fig. 2: Relative Effects of the Different Rate Constants on the Dynamics of the Technological Gap and on the Steady State Value

\section{Model checking in Iran nanotechnology}

First sparkles of nanotechnology in Iran were lit in 2001, and nanotechnology strategic studies began by the command of the former Iranian president. Two years after the beginning of the studies, Iran Nanotechnology Initiative Council was established in 2003. The Council prepared a nanotechnology strategic plan for the next two years, and it handed the plan over to the cabinet. The plan was approved in 2005 by the cabinet. Policies and strategic plans for the improvement and development of nanotechnology were approved in 2006. Iran Nanotechnology Initiative Council created various workgroups for the development of nanotechnology, among which mention can be made of Industry and Market Workgroup, Tech-Market Services Corridor, Nanotechnology Development Workgroup, Human Resources Development Workgroup, Technology Infrastructures Workgroup, Promotion and Culture-making Workgroup, International Affairs Workgroup, and Policy-making and Evaluation Workgroup.

In this paper, we have presented a particular quantitative model of technology transfer and the relationship between leader and follower, and we have demonstrated that this particular approach is useful in describing observed behavior in 
this important area. Complete exploration of the insights provided by the model will require detailed analyses in a variety of cases involving different technologies and different countries. The model for the study of nano-technology in four countries, Middle East( Iran, Turkey, Saudi Arabia and Malaysia),Given the technology leader in this area and in Asian countries ( South Korea, Japan and Iran) to compare the situation in Asia and for two countries (Iran and America) to determine the status of technology with leading technology are done.

In order to illustrate the model, according to surveys carried out and the consult the Experts we have chosen a single parameter P by which to compare Iran and other countries nanotechnology development. Our choices are the Patent applications of nanotechnology and the national priorities of Nanoscience. Other measures, such as the following table were considered, but data for these factors in all countries were not readily available.

Table 1: Indicators and Variables, Technological Efficiency of Nanotechnology

\begin{tabular}{|c|c|c|c|}
\hline Variable & Indicator & Variable & Indicator \\
\hline \multirow{2}{*}{ Investment } & $\begin{array}{l}\text { Share research and development } \\
\text { costs of GDP }\end{array}$ & \multirow{10}{*}{ 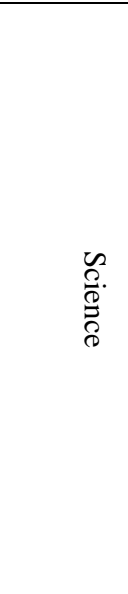 } & National priorities of Nanoscience \\
\hline & $\begin{array}{l}\text { Public investment in science and } \\
\text { nanotechnology }\end{array}$ & & Nano articles for the GDP ppp \\
\hline \multirow[b]{2}{*}{ Human Capital } & Researchers capita R \& D & & The total number of citations of nano articles \\
\hline & $\begin{array}{l}\text { Number of faculty members are } \\
\text { active in nanotechnology }\end{array}$ & & Articles capita Nano \\
\hline \multirow{3}{*}{ Technology } & $\begin{array}{l}\text { Patent applications of } \\
\text { nanotechnology }\end{array}$ & & The local share of Nanoscience \\
\hline & $\begin{array}{l}\text { The number of nanotechnology } \\
\text { patents / Articles of nano }\end{array}$ & & $\begin{array}{l}\text { Contribution to international cooperation in the } \\
\text { production of Nanoscience }\end{array}$ \\
\hline & Nanotechnology patents & & Index (h-Index), Articles Nanotechnology \\
\hline \multirow{3}{*}{ Industry } & GDP & & Number of Nanotechnology \\
\hline & GDP (purchasing power parity) & & Average references per article \\
\hline & $\begin{array}{l}\text { GDP per capita in purchasing } \\
\text { power }\end{array}$ & & Research centers in nanotechnology \\
\hline
\end{tabular}

To analyze the provided model, two-selected variables were selected. Studies have been conducted on two levels: At first, we have investigated in four countries, which are leading in Nanotechnology in the Middle East (Starting with the National priorities and then using a variable of patent application rate in Nanotechnology).

Second, the comparison is considered between Iran and two leading countries in Asia about Nanotechnology. In addition, the 1404 document is the main reason of selecting these exact countries to put in check in the Middle East. Indeed, it is stated in the 1404 document that Iran must be a supreme leader of science and technology in the whole region at the end of 1404. Besides, selection of other Asian countries, including Japan and South Korea is another reason of comparing Iran with top Asian countries in nanotechnology.

Furthermore, it is fundamental that the default provided analysis condition should be considered the equality of these countries in initial conditions.

As regards all of these analyzed countries almost commence this process over a period of time simultaneously and it cannot be out of people's mind. Therefore, the terms of the model are reliable.

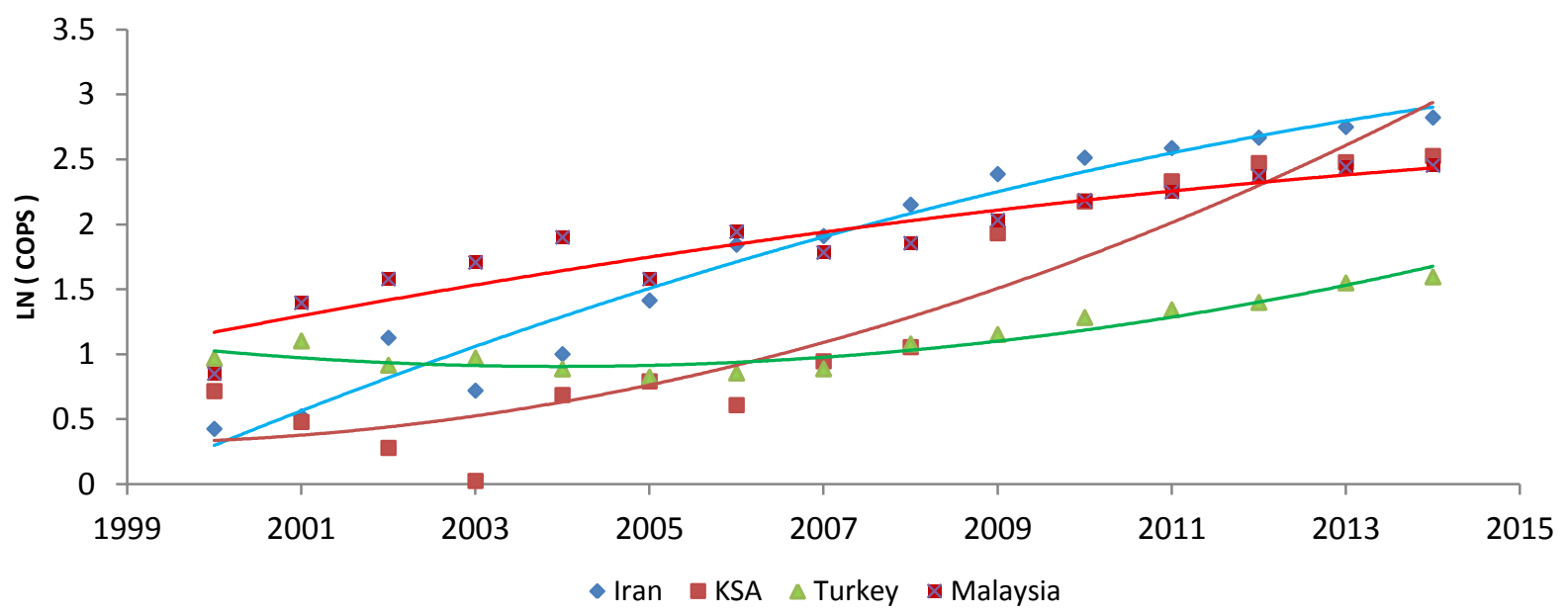

Fig. 3: Technological Productivity National Priorities in the Production Science (Middle East) 


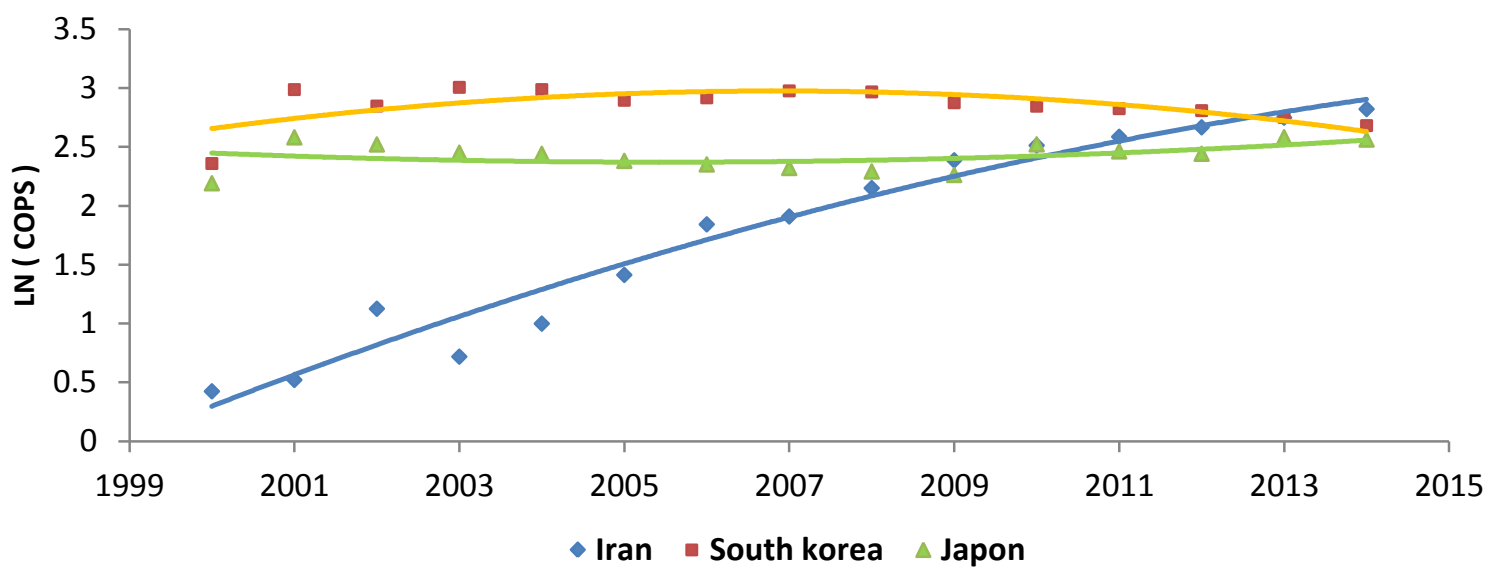

Fig. 4: Technological Productivity National Priorities in the Production Science (Asia)

The analysis, which is conducted in Figures 3 and 4, are characterized by variable of national priorities in producing Nano sciences, which depict the state of trajectory, status and the position of Nano sciences in Iran and other compared countries. The variable represents the proper trajectory of Iran in Nano technology.

The growth rate of technological efficiency of Iranian Nano technology is more favorable in comparison with Turkey and Malaysia.

But, evidences show that, Saudi Arabia has reached the higher growth and technological efficiency in the similar period of time. Therefore, it can be as an alert for Iran to keep its rightful place in the Middle East. However, in the same analysis, which is done, Iran has a better growth rate in comparison with other top leading countries in Asia. The achieved outputs can be evaluated by another variable to verify the results. In order to gain goals, it is tried to analyze the variable of patent application rate in nanotechnology once more.

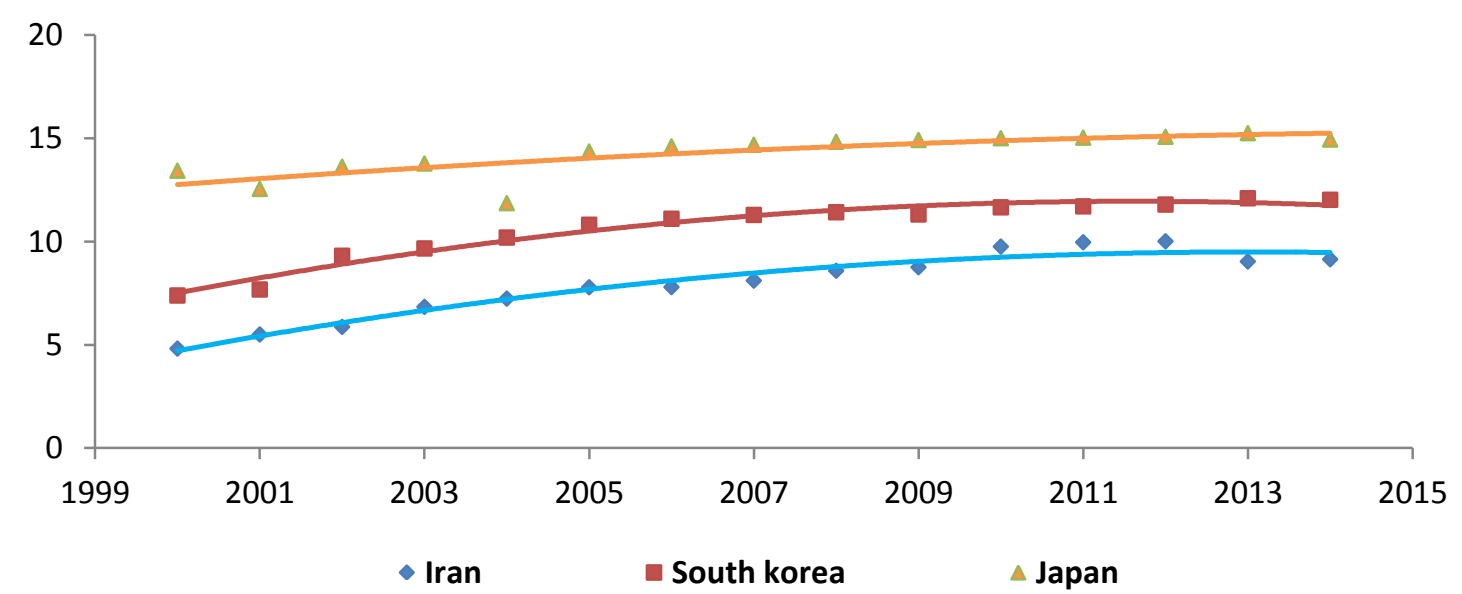

Fig. 5: Technological Productivity Patent Applications of Nanotechnology (Asia)

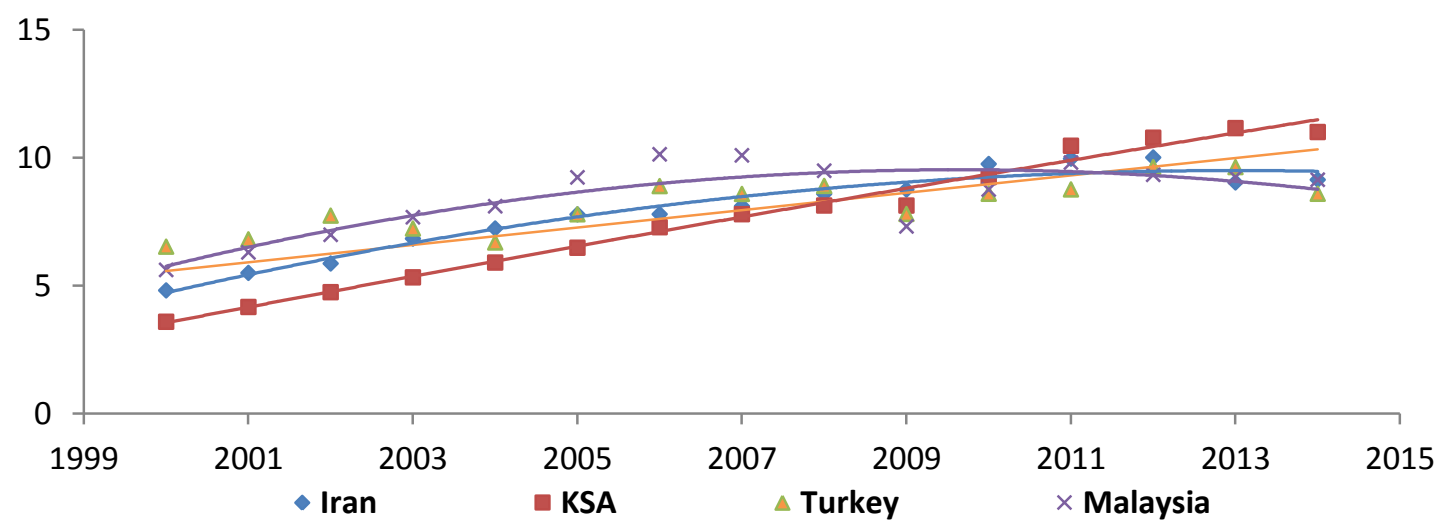

Fig. 6: Technological Productivity Patent Applications of Nanotechnology (Middle East) 
The model analysis using nanotechnology patent applications are shown in Figures 5 and 6 . The results have been confirmed the pervious step. It indicates that Iran has a good efficiency rate in nanotechnology. Similarly, like the previous analysis, the growth and technological efficiency rate of Saudi Arabia has been approved again.

\section{Second step}

The second step of analysis consists of determining the stochastic frontier. It is assumed that each country $i$, group $k=1$, 2, 3, 4 makes use of its factors according to group specific technology. The stochastic group-k frontier model to be estimated will be defined as:

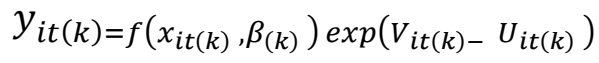

$y_{i t(k)}$ Is the output of country, $x_{i t(k)}$ is the vector of inputs and $\beta_{(k)}$ is the vector of unknown parameters. $V_{i t}=$ error term identically $\left(V_{i t} \sim N\left(0, \sigma K_{v(k)}^{2}\right)\right)$

$U_{i t}=$ Non-negative error term independent from Vit, which represents the technical inefficiency.Uit is distributed independently as a zero-truncated normal Process.

$T E_{i}^{k}=\frac{Y_{i t}}{f\left(x_{i t(k)}, \beta_{(k)}\right) \exp \left(V_{i t(k)}\right)}=\exp ^{-U_{i t(k)}}$

$T E_{i}$ Which allow us to examine the performance of the i-th country relative to the individual group frontier cannot be used to measure technological capability as countries from different regions operate under different production technologies. The metafrontier production function model for the county (i) is expressed by:

$Y_{i t}^{*}=f\left(X_{i t}, \beta^{*}\right) \exp \left(V_{i t}^{*}-U_{i t}^{*}\right)$

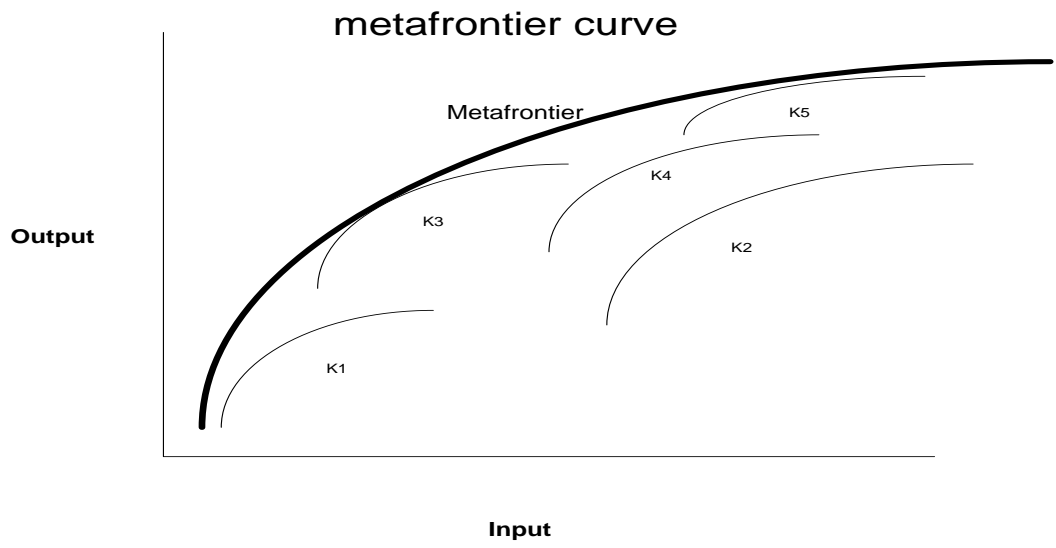

Fig. 6: Metafrontier Curve

$Y_{i t}^{*}$ is the metafrontier output that dominates all group frontiers and $\beta^{*}$ expressed the vector of parameters for the metafrontier function and results from solving the following linear program [19]

$$
\left\{\begin{array}{c}
\min _{\beta}{ }^{*} \sum_{i=1}^{I} \sum_{t=1}^{T}\left|\ln Y_{i t}-\ln Y_{i t}{ }^{*}\right| \\
\text { subject to } \ln \left(f\left(X_{i t}, \beta^{*}\right)\right) \geq \ln \left(f\left(X_{i t(k)}, \beta_{(K)}\right)\right) \\
\text { for all } k=1, \ldots, s
\end{array}\right.
$$

We estimate technical efficiency with respect to the metafrontier as:

$T G R_{i}=\frac{f\left(x_{i t(k)}, \beta_{(k)}\right)}{f\left(x_{i t}, \beta^{*}\right)}$

The ratio is equal to one when the country's technology frontier coincides with the metatechnology frontier. Countries closer to the metafrontier have higher technology gap ratios and are considered as more advanced technologically. An 
increase over time in the technology gap ratio indicates a technological catch-up for which we want to test the main determinants. The technical efficiency relative to the metafrontier is defined as:

$\mathrm{TE}_{\mathrm{it}}^{*}=\mathrm{TE}_{\mathrm{it}} * \mathrm{TGR}_{\mathrm{it}}$

Table 2: Estimates for Parameters of the Stochastic Frontier Models

\begin{tabular}{|c|c|c|c|c|c|c|}
\hline & Iran & Japan & turkey & South korea & pooled frontier & Metafrontier \\
\hline \multirow{2}{*}{ Constant } & -1.253 & -0.007 & 1.255 & 1.538 & 1.097 & 3.196 \\
\hline & $(1.770)$ & $(0.313)$ & (1.190) & $(0.029)$ & $(0.110)$ & \\
\hline \multirow{2}{*}{ Trend } & -0.246 & -0.043 & -0.100 & -0.043 & -0.075 & -0.067 \\
\hline & $(0.009)$ & $(0.003)$ & $(0.004)$ & $(0.002)$ & $(0.004)$ & \\
\hline \multirow{2}{*}{ Technology } & 0.494 & 1.088 & 0.943 & 0.852 & 0.882 & 0.869 \\
\hline & $(0.035)$ & $(0.045$ & $(0.012)$ & $(0.002)$ & $(0.021)$ & \\
\hline \multirow{2}{*}{ Science } & 0.841 & 0.045 & $0.143^{*}$ & 0.537 & 0.161 & 0.167 \\
\hline & $(0.076)$ & $(0.003)$ & $(0.080)$ & $(0.040)$ & $(0.035)$ & \\
\hline \multirow{2}{*}{ Human capital } & 0.244 & -0.013 & 0.022 & -0.385 & -0.042 & -0.179 \\
\hline & $(0.009)$ & $(0.002)$ & $(0.005)$ & $(0.004)$ & $(0.101)$ & \\
\hline \multirow[b]{2}{*}{$\sigma$} & 20.143 & 0.309 & 0.94 & 0.69 & 0.34 & \\
\hline & $(0.020)$ & $(0.162)$ & $(0.550)$ & $(0.312)$ & $(0.083)$ & \\
\hline & 0.97 & 0.85 & 0.99 & 0.99 & 0.99 & \\
\hline$\gamma$ & $(0.004)$ & $(0.028)$ & $(0.008)$ & $(0.001)$ & $(0.012)$ & \\
\hline Log-L & 380.85 & 288.89 & 111.5 & 575.06 & 137.35 & \\
\hline
\end{tabular}

The stochastic frontier model is estimated assuming the Cobb-Douglass function form:

$Y_{i t}=A_{i t} K_{i t}^{\alpha_{k}} L_{i t}^{\beta_{k}} H_{i t}^{\gamma_{k}} \exp \left(V_{i t}-U_{i t}\right), i=1, \ldots, N g t=1, \ldots, T^{-}$

The term $Y_{i t}$ is the output, $K_{i t}$ is the technology, $H_{i t}$ is the human capital, $L_{i t}$ is the science and $A_{i t}$ is the total factor catch -up, expressed as exp $\left(\delta_{i t}-\mathrm{tk}_{\mathrm{t}}\right)$

The analysis uses data from balanced panel observed for the period 2000 to 2013. Table below provides average technical efficiency and technology gap scores for countries over the period 2000-2013.

Table 3: Average Technical Efficiency Scores and Technology Gap

\begin{tabular}{|c|c|c|c|c|c|c|c|c|c|}
\hline & $\left(\mathrm{TE}_{\mathrm{it}}\right)$ & $\left(\mathrm{TGR}_{\mathrm{it}}\right)$ & $\left(\mathrm{TE}_{\mathrm{it}}^{*}\right)$ & Iran & $\begin{array}{l}\text { South } \\
\text { korea }\end{array}$ & Japan & turkey & $\mathrm{KSA}$ & Average \\
\hline 2000 & 0.9602 & 0.1958 & 0.188 & 0.102 & 0.648 & 0.124 & 0.007 & 0.098 & 0.196 \\
\hline 2001 & 0.9603 & 0.1882 & 0.1807 & 0.098 & 0.628 & 0.117 & 0.007 & 0.092 & 0.188 \\
\hline 2002 & 0.9592 & 0.087 & 0.0834 & 0.072 & 0.247 & 0.061 & 0.006 & 0.049 & 0.087 \\
\hline 2003 & 0.9594 & 0.2108 & 0.2022 & 0.175 & 0.599 & 0.147 & 0.015 & 0.118 & 0.211 \\
\hline 2004 & 0.9597 & 0.1993 & 0.1912 & 0.168 & 0.564 & 0.141 & 0.014 & 0.111 & 0.199 \\
\hline 2005 & 0.96 & 0.1879 & 0.1804 & 0.161 & 0.529 & 0.134 & 0.012 & 0.104 & 0.188 \\
\hline 2006 & 0.9603 & 0.1772 & 0.1702 & 0.154 & 0.496 & 0.127 & 0.01 & 0.098 & 0.177 \\
\hline 2007 & 0.9605 & 0.1725 & 0.1657 & 0.148 & 0.492 & 0.121 & 0.009 & 0.093 & 0.173 \\
\hline 2008 & 0.9608 & 0.1625 & 0.1562 & 0.142 & 0.465 & 0.11 & 0.008 & 0.087 & 0.163 \\
\hline 2009 & 0.9611 & 0.1525 & 0.1466 & 0.136 & 0.436 & 0.101 & 0.007 & 0.082 & 0.153 \\
\hline 2010 & 0.9614 & 0.145 & 0.1394 & 0.13 & 0.417 & 0.094 & 0.006 & 0.077 & 0.145 \\
\hline 2011 & 0.9616 & 0.1384 & 0.1331 & 0.124 & 0.4 & 0.09 & 0.005 & 0.072 & 0.138 \\
\hline 2012 & 0.9619 & 0.1312 & 0.1262 & 0.118 & 0.381 & 0.084 & 0.005 & 0.068 & 0.131 \\
\hline \multirow[t]{2}{*}{2013} & 0.9621 & 0.1242 & 0.1195 & 0.112 & 0.362 & 0.079 & 0.004 & 0.064 & 0.124 \\
\hline & & & & 0.113 & 0.51 & 0.155 & 0.013 & 0.15 & \\
\hline
\end{tabular}

The average technical efficiency of the Iran relative to the metatechnology is only about 0.113 . This suggests that Iran is highly inefficient relative to the metafrontier. Among the five countries, South Korea has on average the better performance with a technology gap ratio of 0.51 on average

\section{The technology gap}

Using the model presented in part one $\mathrm{G}=\left(\mathrm{K}_{\mathrm{L}}-\mathrm{K}_{\mathrm{F}}\right) / \mathrm{K}_{\mathrm{T}}+\left[\left(\mathrm{x}_{\mathrm{L}}^{0}+\mathrm{x}_{\mathrm{F}}^{0}-\left(\mathrm{K}_{\mathrm{L}}-\mathrm{K}_{\mathrm{F}}\right) / \mathrm{K}_{\mathrm{T}}\right.\right.$ it can be calculated the gap between Iran and other leading countries.

Values of $\mathrm{K}_{\mathrm{T}} \cdot \mathrm{K}_{\mathrm{F}} \cdot \mathrm{K}_{\mathrm{L}}$ can be determined due to the time of starting nanotechnology, the initial conditions at the beginning of this process and the efficiency rate of nanotechnology in Iran. During these years, the technological growth rate of nanotechnology has been appropriate. Also suitable knowledge progress was existed. 
Value of 2.0 can be considered for $\mathrm{K}_{\mathrm{T}}$. As it was mentioned before, it is contemplated that the smaller amount of $\mathrm{K}_{\mathrm{T}}$, the more insufficient of knowledge progress in the relevant field. The value of $\mathrm{K}_{\mathrm{F}}$ in 0.2 and $\mathrm{K}_{\mathrm{L}}$ in 0.5 are contemplated due to the fact that, Iran's nanotechnology considered as an essential element in the earliest years of introducing.

The following table shows the gap between Iran and America as the leading of nanotechnology from 2001 until 2014. As it is shown in the table, the results indicate no significant change towards the gap between Iran and the United States of America in nanotechnology.

The amount of this gap between these countries is just about 0.3 in 13 years (16.4 in 2001 and it has reached to 16.7 in 2014). As a matter of fact, the gap should be considered as the growth rate of other technologies. As we know, there is a huge gap between Iran and the U.S in technological and sciences. Besides, if there was not a proper strategy in Iran during these years it would be definitely much more technological gap between Iran and the U.S.

Table4: Nanotechnology Gap between Iran and America

\begin{tabular}{cccccc}
\hline Year & Iran & leading country (America) & $\mathrm{x}_{\mathrm{L}}$ & $\mathrm{x}_{\mathrm{F}}$ & $\begin{array}{c}\text { Gap calculated per years } \\
\text { towards the leading }\end{array}$ \\
\hline 2000 & 530 & $1,035,159$ & 13.65007 & 6.072877 & 16.4 \\
2001 & 830 & $5,319,168$ & 15.08683 & 6.321426 & 17.8 \\
2002 & 1390 & $94,841,149$ & 17.76771 & 6.637073 & 20.3 \\
2003 & 3320 & $9,124,164$ & 15.22644 & 7.307726 & 18.7 \\
2004 & 2390 & $10,888,163$ & 15.20319 & 6.779053 & 18.0 \\
2005 & 2410 & $11,286,160$ & 15.03909 & 6.587386 & 17.7 \\
2006 & 2430 & $12,298,160$ & 14.92496 & 6.395651 & 18.1 \\
2007 & 5360 & $13,404,159$ & 14.81108 & 6.986723 & 18.5 \\
2008 & 6350 & $12,879,160$ & 14.57112 & 6.956215 & 18.3 \\
2009 & 17280 & $15,230,162$ & 14.53879 & 7.757309 & 18.1 \\
2010 & 21280 & $14,562,157$ & 14.29394 & 7.765527 & 17.1 \\
2011 & 22290 & $15,695,157$ & 14.16886 & 7.611897 & 16.7 \\
2012 & 8400 & $17,177,155$ & 14.05909 & 6.435991 & 6.342065 \\
2013 & 9340 & $15,469,158$ & 13.75436 & & \\
\hline
\end{tabular}

It can be concluded that technological efficiency is in an appropriate rate, on account of the fact that, the gap has remained fairly constant over these years. Moreover, the impact of other technologies on the scientific environment should be considered. It seems that Iranian nanotechnology demand new avenues which is called quick access. In the matter of today's business environment and the gap which is between Iran and its competitors.

Therefore, seven following approaches can facilitate this process.

- Window of opportunity

- Initial condition

- Integration of Knowledge

- Internal structures

- Investment

- Macroeconomic policy and program development

- $\quad$ Social and institutional conditions

\section{Conclusion}

It is determined that Iranian approach towards nanotechnology and the selection of the paths is an accurate method and it is completely matched with other international attitudes in three steps. The initial step of investigations, which are done about the technology and efficiency, gaps between Iran and the Middle East (to achieve the vision of 1404 document). Then, the next step was about the leading countries in Asia. And the last step is the investigating about United States as the leading country of nanotechnology.

The results clearly indicated that Iran could use the gate of this opportunity to gain its goals. Iran used its crucial entrance in nanotechnology and also the proper mutation is implemented towards this golden chance. Iran could lower the technological gap between itself and the world leaders in nanotechnology and it has pursued the right direction without dependence despite of technological spillovers from other areas in leading countries. The notable point is about the analysis result about some countries like Saudi Arabia, which has gained the suitable place in nanotechnology in these years.

With respect to the strategies, which are selected in the 1404 document, If Iran wants to be supreme leather in the Middle East; it should have a better review of some emphasized topics about the gate opportunity in nanotechnology. In this research, it is attempted to evaluate the efficiency of technology and technology gap with using two indicators. Thus, the results and outputs of these two indicators should be fully consistent with each other. 
The results have also confirmed the given conditions but it suggests that despite of the appropriate investment policy and national perspective towards nanotechnology, Iran bears a weakness in industrial outputs and trades. Consequently, other countries in the Middle East such as Saudi Arabia, which is the main rival of Iran, are in a better position.

Saudi Arabia could ameliorate its technological process and it could successfully lessen the gap between itself and Iran during the previous years.

It seems that Saudi Arabia goes at a good pace in this process and it makes Iran not to make progress rapidly in the field of nanotechnological efficiency than before. Hence, it can be highly recommended that Iran should have a better domestic approach towards this issue. In addition, having suitable industrial policies and implementing facilities to ease economic and industrial outputs in this particular field.

\section{References}

[1] Lall, S. and C. Pietrobelli, National technology systems in sub-Saharan Africa. International Journal of Technology and Globalisation, 2005. 1(3): p. 311-342. http://dx.doi.org/10.1504/IJTG.2005.008746.

[2] Burkett, P. and M. Hart-Landsberg, A critique of “catch-up” theories of development. Journal of Contemporary Asia, 2003. 33(2): p. 147-171. http://dx.doi.org/10.1080/00472330380000101.

[3] Chesbrough, H.W., Open innovation: The new imperative for creating and profiting from technology2003: Harvard Business Press

[4] Radosevic, S., International technology transfer and catch-up in economic development. 1999.

[5] Grossman, G.M. and E.L.-C. Lai, International protection of intellectual property: Corrigendum. American Economic Review, 2006. 96(1): p. 456. http://dx.doi.org/10.1257/000282806776157506.

[6] Vedeler, C., Productivity Growth in South Africa and the Effects of Foreign Direct Investments: A time series analysis. 2013.

[7] Falvey, R., N. Foster, and D. Greenaway, Imports, exports, knowledge spillovers and growth. Economics Letters, 2004. 85(2): p. 209-213. http://dx.doi.org/10.1016/j.econlet.2004.04.007.

[8] Patel, P. and K. Pavitt, National innovation systems: why they are important, and how they might be measured and compared. Economics of innovation and new technology, 1994. 3(1): p. 77-95. http://dx.doi.org/10.1080/10438599400000004.

[9] Acemoglu, D. and J.A. Robinson, Political losers as a barrier to economic development. The American Economic Review, 2000. 90(2): p. 126-130. http://dx.doi.org/10.1257/aer.90.2.126.

[10] $\mathrm{Mu}, \mathrm{Q}$. and K. Lee, Knowledge diffusion, market segmentation and technological catch-up: The case of the telecommunication industry in China. Research Policy, 2005. 34(6): p. 759-783. http://dx.doi.org/10.1016/j.respol.2005.02.007.

[11] Abramovitz, M., Thinking about growth: And other essays on economic growth and welfare 1989: Cambridge University Press. http://dx.doi.org/10.1017/CBO9780511664656.

[12] Silverberg, G. and B. Verspagen, Learning, innovation and economic growth: a long-run model of industrial dynamics. Industrial and Corporate Change, 1994. 3(1): p. 199-223. http://dx.doi.org/10.1093/icc/3.1.199.

[13] Lundvall, B.-Ä. and B. Johnson, The learning economy. Journal of industry studies, $1994 . \quad 1(2)$ p. $23-42$. http://dx.doi.org/10.1080/13662719400000002.

[14] Mazzoleni, R. and R.R. Nelson, Public research institutions and economic catch-up. Research Policy, 2007. 36(10): p. 1512-1528. http://dx.doi.org/10.1016/j.respol.2007.06.007.

[15] Manca, F., Technology catch-up and the role of institutions. Journal of macroeconomics, 2010. 32(4): p. 1041-1053. http://dx.doi.org/10.1016/j.jmacro.2010.07.004.

[16] Póvoa, L.M.C. and M.S. Rapini, Technology transfer from universities and public research institutes to firms in Brazil: what is transferred and how the transfer is carried out. Science and Public Policy, 2010. 37(2): p. 147-159. http://dx.doi.org/10.3152/030234210X496619.

[17] Nelson, R.R. and E.S. Phelps, Investment in humans, technological diffusion, and economic growth. The American Economic Review, 1966. 56(1/2): p. $69-75$

[18] Dollar, D. and A. Kraay, Institutions, trade, and growth. Journal of monetary economics, $2003.50(1)$ : p. $133-162$. http://dx.doi.org/10.1016/S0304-3932(02)00206-4.

[19] Battese, G.E., D.P. Rao, and C.J. O'Donnell, A metafrontier production function for estimation of technical efficiencies and technology gaps for firms operating under different technologies. Journal of Productivity Analysis, 2004. 21(1): p. 91-103. http://dx.doi.org/10.1023/B:PROD.0000012454.06094.29. 